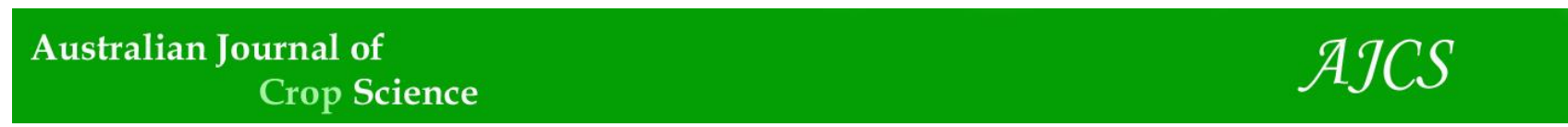

AJCS 12(01):32-43 (2018)

ISSN:1835-2707

doi: 10.21475/ajcs.18.12.01.pne570

\title{
Improving the prediction of potato productivity: APSIM-Potato model parameterization and evaluation in Tasmania, Australia
}

\author{
Dinah Borus $^{1 *}$, David Parsons ${ }^{1,2}$, Mark Boersma ${ }^{1}$, Hamish Brown ${ }^{3}$, Caroline Mohammed ${ }^{1}$ \\ ${ }^{1}$ Tasmanian Institute of Agriculture/School of Land and Food, University of Tasmania, Australia \\ ${ }^{2}$ Department of Agricultural Research for Northern Sweden, Swedish University of Agricultural Sciences, Umeå, \\ Sweden \\ ${ }^{3}$ The New Zealand Institute of Plant and Food Research, Lincoln, New Zealand
}

*Corresponding author: djborus@utas.edu.au

\begin{abstract}
Crop growth models are required to be extensively evaluated against actual data from field grown plants in order to have confidence in their prediction of crop productivity under various management options or a future changed climate. We evaluated the ability of the APSIM-potato model to predict production, phenology, and N-uptake of potato (Solanum tuberosum L.) under Tasmanian conditions. On-farm monitoring plots were established in north-west Tasmania within four different well-managed potato fields grown during the 2012/13 cropping season. Detailed soil and crop data sets measured in the on-farm plots planted with two potato cultivars, 'Russet Burbank' and 'Moonlight' were used to parameterise and evaluate the model. The model realistically reproduced the observed tuber yield with high precision (a mean N-RMSE of $15.4 \%$ and modelling efficiency of 1.0 for both cultivars). Measured mean dry matter (TDM) tuber yield was $17 \mathrm{t} \mathrm{ha}^{-1}$ for 'Russet Burbank' with a simulated yield of $20 \mathrm{t} \mathrm{ha}$ '. For 'Moonlight' simulated TDM yield was $16.0 \mathrm{t} \mathrm{ha}^{-1}$ compared to measured yield of $15.1 \mathrm{t} \mathrm{ha} \mathrm{a}^{-1}$. The simulation results provide insight on the model performance under Tasmanian conditions. The results suggest that the model has potential to be used for purposes such as simulating productivity under various management options and climate change impact studies. Additional experiments are however required to improve cultivar specific input parameters such as phenology, leaf area and leaf duration and other functions that needs further refinement to improve model ability to simulate plant organs beside the tuber.
\end{abstract}

Keywords: APSIM-potato model, climate change, parameterisation, evaluation, simulation, tuber dry matter yield. Abbreviations: APSIM_Agricultural Production Systems sIMulator, DAP_Days after Planting, FW_Fresh weight, LB_Lower Barrington, MS_Main stem, SSF_Sassafras, SC_Stage code, TDM_Tuber dry matter, TVRF_Tasmanian Institute of Agriculture Vegetable Research Facility.

\section{Introduction}

Potato (Solanum tuberosum L.) is the third most important food crop, grown in most continents (Birch et al. 2012; Bradshaw and Bonierbale 2010; FAO 2015) and yet the application of simulation models has lagged behind other major crops (White et al. 2011). In Australia, the Agricultural Production Systems sIMulator potato model (APSIM-potato model) is still in its infancy compared to other plant modules such as APSIM-wheat, maize and sorghum. For example, the list of APSIM publications was 551 as at June 30, 2014 (Holzworth et al. 2014) but there were very few publications on potato.

Potato is the leading vegetable produced in Australia (ABS 2014). South Australia, Victoria and Tasmania are the leading potato producing States. Together, they contribute over 70\% of the national total tuber production (ABS 2014). In Tasmania, potato is the mainstay of the vegetable industry representing over two thirds of the industry volume (ABS 2014; AUSVEG 2014). Over $80 \%$ of the potatoes produced in Tasmania are sold to the other States and the remainder is consumed locally (DPIPWE 2014). Potatoes are mainly cultivated in Tasmania's north-west, featuring red ferrosol soils, but with the expansion of irrigation schemes, potato production is increasingly moving to the less traditional sandy duplex soils of the Midlands and the north-east of Tasmania. The availability of quality irrigation water may not be a constraint in the near future in Tasmania because irrigation programs are expanding (DPIPWE 2015) but there is an urgent need for research to underpin potato production so that it is profitable and environmentally sustainable.

Crop simulation modelling can be applied in investigative studies in a wide range of problem domains (Fleisher et al. 2017; Haverkort et al. 2013; White et al. 2011) such as the response of potato to different climates, soil types and management options. Crop growth models need to be accurately parameterized against measured data before they can be applied in new areas and for new cultivars (Boote et al. 2010; Palosuo et al. 2011; Raymundo et al. 2014). For this to be done, a robust and reliable crop growth model that is well calibrated is needed. 
The first potato model, Sands Model, was developed about five decades ago (Raymundo et al. 2014). Since then, over 30 potato crop growth models have been developed. They include SUBSTOR-Potato, LINTUL-Potato, SOLANUM, APSIMPotato, SPUDSIM, POMOD, SIMPOTATO and Potato Calculator (Fleisher et al. 2017; Raymundo et al. 2014; Saue and Kadaja 2014). Most potato models have not been comprehensively tested with actual field data and some have not been used even for a single application. APSIM (which contains a suite of modules for different crops) is used by researchers in many parts of the world. While the APSIM-potato model has been tested and calibrated with a number of data sets from long-term experiment in Lincoln, New Zealand and has accurately reproduced effects of different rates of $\mathrm{N}$-fertilizer, sowing dates, plant density and irrigation treatments, there are knowledge gaps that need to be addressed before the model is widely used (Brown et al. 2011).

A crop growth model is considered robust if it can simulate observed data with acceptable accuracy. The current study sought, under Tasmanian potato growing conditions, to parameterise the APSIM-potato model with two different cultivars ('Russet Burbank' and 'Moonlight') and to evaluate model performance in simulating, in-season and end-ofseason biomass, tuber yield and N-uptake of the potato. This is the first time APSIM-potato has been tested in Australia. This study targets the question: Can the APSIM-potato model reproduce the observed data with reasonable accuracy under Tasmanian potato growing conditions?

\section{Results}

\section{Crop performance at the on-farm monitoring plots}

There was little variation in the weather conditions (Table 1) during the growing seasons across the trial sites or in the cultural practices by cultivar (e.g. nitrogen application and irrigation water supply, Table 2). All the sites recorded high emergence rate with an average of $98.2 \%$ for 'Moonlight' and $89.5 \%$ for 'Russet Burbank'. 'Russet Burbank' has a higher potential yield compared to 'Moonlight'. The mean end-of-season tuber yield was $73.4 \mathrm{t} \mathrm{FW} \mathrm{ha}^{-1}$ (fresh weight) across the cultivars with a mean of 77.8 and $69 \mathrm{t} \mathrm{FW} \mathrm{ha}^{-1}$ for 'Russet Burbank' and 'Moonlight' respectively. Tuber yield in Tasmania ranges from 48 to $75 \mathrm{t} \mathrm{FWha}^{-1}$ with an average tuber yield of $48.5 \mathrm{t} \mathrm{FWha}{ }^{-1}$ for the period 2003 to 2013 (ABS 2014).

\section{Evaluation of model simulation}

Number of leaves per main stem (MS): The simulated rate of leaf appearance was faster than the observed rate (Fig 1.) and subsequently the simulated final number of leaves appearing on each main stem was higher than the number observed throughout the growing season for both cultivars across the sites. The index of agreement was good with Root Mean Squared Error (normalised, N-RMSE) values of 27.5\% for 'Russet Burbank' at Lower Barrington (LB1) and $16.4 \%$ at Sassafras (SSF) and for 'Moonlight' the values were $15.4 \%$ at Tasmanian Institute of Agriculture Vegetable Research Facility (TVRF) and $15.8 \%$ at LB2 (Table 3 and 4). Modelling efficiency (EF) was good especially for 'Moonlight' with a mean of 0.7 for both sites and 0.4 for 'Russet Burbank'.
Aboveground biomass: Graphically, simulated values were close or equal to the observed values during the vegetative and early tuber growth stage (up to 80 days after planting, DAP for the two cultivars) for both leaf and stem dry biomass (Fig 2.). However, the measured maximum leaf and stem biomass were higher than the simulated values. Also, the simulated rate of leaf senescence after reaching the peak was faster and this gave lower values of simulated leaf dry biomass in the second half of the growth cycle. N-RMSE values for 'Russet Burbank' (Table 3) grown at LB1 were $25.2 \%$ for leaf and $25.4 \%$ for stem, $36.9 \%$ for leaf and $29.8 \%$ for stem at SSF. Compared to 'Russet Burbank', the index of agreement was poorer for 'Moonlight' with N-RMSE values of $40.9 \%$ for leaf and $41.7 \%$ for stem at TVRF, $44.9 \%$ for leaf and $32.7 \%$ for stem for the crop grown at LB2 (Table 4 ).

The prediction varied per location with the best agreement (N-RMSE <30\%) between simulated and observed leaf and stem biomass being that of 'Russet Burbank' at LB1. The EF values, an average of 0.6 for leaf and 0.7 for stem for 'Russet Burbank' implies that model performance was within acceptable range for both leaf and stem dry matter. In contrast, low EF values for 'Moonlight', a mean of -0.6 for leaf and 0.3 for stem indicates poor simulation results.

Leaf area index: Simulated Leaf area index (LAI) values (Fig.3) fitted well with the observed values both for 'Russet Burbank' and 'Moonlight' during the vegetative and early tuber growth stage, (up to 60 DAP for 'Moonlight' and 80 DAP for 'Russet Burbank'). However, there was large deviation afterwards with measured maximum LAI being higher than the simulated values for 'Russet Burbank' and lower for 'Moonlight'. Similarly, there was deviation in the decline of LAI values after reaching the peak with simulated values declining faster than observed for both cultivars. NRMSE values for 'Russet Burbank' at LB1 was $25.4 \%$ and $35.1 \%$ at SSF and for 'Moonlight' the values were $36.9 \%$ at TVRF and $48.0 \%$ at LB2 (Table 3 and 4). Notably, the simulation followed a similar trend as that of leaf biomass with the best index of agreement (N-RMSE of $<30 \%$ ) between simulated and observed LAI being that for 'Russet Burbank' at LB1.

Compared to LB1, the crop at SSF produced excessive growth of haulms and hence high LAI possibly as a result of high number of irrigation events (data not shown) and high amount of irrigation water (Table 2) supplied coupled with higher nitrogen application rates. The excessive growth of haulms was not fully captured by the model. Across the sites, a high N-RMSE (>30\%) values for 'Moonlight' indicates unsatisfactory index of agreement between the simulated and observed LAI. Also, low EF values, -0.2 for 'Moonlight' at TVRF and -2.7 at LB2 is an indication of poor model performance in simulating LAI for the cultivar.

Tuber yield: The agreement between the simulated and the observed tuber dry matter (TDM) was good for both cultivars and across localities (Fig. 4). N-RMSE values for 'Russet Burbank' grown at LB1 was $13.1 \%$ and $19.5 \%$ at SSF and for Moonlight N-RMSE values were $12.7 \%$ at TVRF and $16.3 \%$ at LB2 (Table 3 and 4). The low N-RMSE values of less than $20 \%$ for all the sites is an indication of high precision and reliability of the APSIM-potato model to predict tuber yield. Also, the high EF values, an average of 1.0 for both cultivars imply an excellent level of model performance. Graphically, the simulated values fitted well with observed 
Table 1. Weather data (temperature, solar radiation, rainfall) from planting to harvesting date at each of the on-farm monitoring plots in north-west Tasmania

\begin{tabular}{llllll}
\hline Data & Units & TVRF & LB1 & LB2 & SSF \\
\hline Mean Tmax & ${ }^{\circ} \mathrm{C}$ & $21 \pm 3.0$ & $20.6 \pm 3.4$ & $20.8 \pm 3.1$ & $20.9 \pm 3.2$ \\
Mean Tmin & ${ }^{\circ} \mathrm{C}$ & $11.1 \pm 3.5$ & $10 \pm 3.6$ & $10.3 \pm 3.4$ & $10.7 \pm 3.6$ \\
Highest temperature & ${ }^{\circ} \mathrm{C}$ & 30.5 & 30 & 30 & 31 \\
Lowest temperature & ${ }^{\circ} \mathrm{C}$ & 2 & 2 & 2.5 & 2.5 \\
$\begin{array}{l}\text { Accumulated growing days degrees at final } \\
\text { harvest }\end{array}$ & ${ }^{\circ} \mathrm{Cd}$ & 2164 & 2004 & 2099 & 2098 \\
Mean Radiation & & & & \\
Total Rainfall & $\mathrm{Mj}{ }^{-2} \mathrm{day}^{-1}$ & $21.6 \pm 5.6$ & $21.6 \pm 5.5$ & $21.2 \pm 5.7$ & $21.9 \pm 5.5$ \\
\hline
\end{tabular}

LB: Lower Barrington 1 and 2, SSF: Sassafras, TVRF: Tasmanian Institute of Agriculture Vegetable Research Facility, Tmax: maximum daily temperature, Tmin: Minimum daily temperature
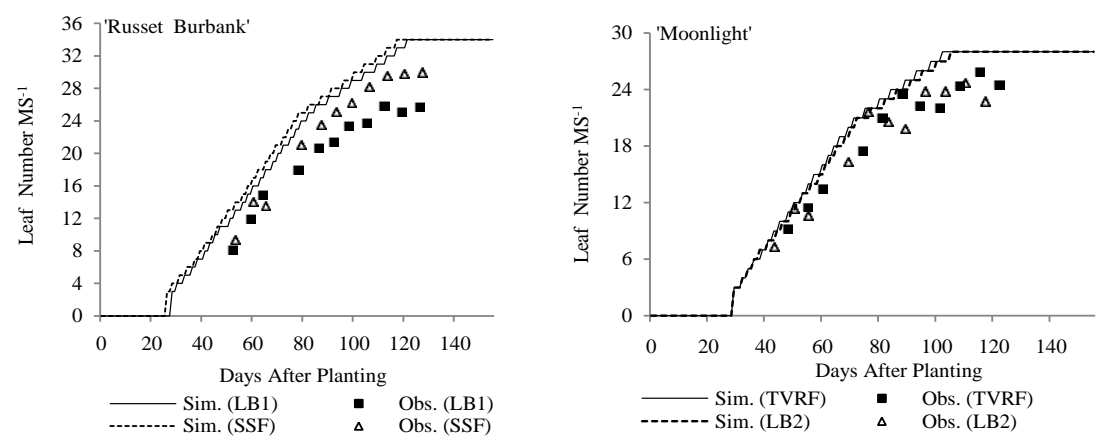

Fig 1. Change in observed and simulated number of leaves appearing on each main stem (MS) over time for 'Russet Burbank' grown at LB1 and SSF and 'Moonlight' grown at TVRF and LB2

Table 2. Management events at each of the on-farm plots used as input parameter data to run the simulations.

\begin{tabular}{lllll}
\hline Management & TVRF & LB1 & LB2 & SSF \\
\hline Cultivar & 'Moonlight' & 'Russet Burbank' & 'Moonlight' & 'Russet Burbank' \\
Planting date & $20 / 10 / 2012$ & $16 / 10 / 2012$ & $25 / 10 / 2012$ & $15 / 10 / 2012$ \\
Tuber emergence date & $13 / 11 / 2012$ & $17 / 11 / 2012$ & $17 / 11 / 2012$ & $13 / 11 / 2012$ \\
Sowing depth (mm) & 175 & 150 & 175 & 150 \\
Row spacing (mm) & 810 & 810 & 810 & 810 \\
Inter-row spacing (mm) & 250 & 300 & 250 & 300 \\
Plant density (plants $\mathrm{m}^{-2}$ ) & 4.9 & 4.1 & 4.9 & 4.1 \\
No. of MS plant $^{-1}$ & 4.6 & 2.0 & 4.1 & 2.0 \\
Stem density (stems $\mathrm{m}^{-2}$ ) & 22.8 & 8.2 & 20.2 & 8.0 \\
N- Application & 95.6 & 338.2 & 95.6 & 328.0 \\
(kg N ha $^{-1}$ ) & & & & 406.6 \\
Total irrigation water applied (mm) & 276.3 & 294.2 & 275.5 & $15 / 03 / 2013$ \\
Final harvesting date & $22 / 03 / 2013$ & $15 / 03 / 2013$ & $28 / 03 / 2013$ & 151 \\
Duration of growing date (days) & 153 & 150 & 154 &
\end{tabular}

Table 3. Statistical comparison between observed and simulated data for 'Russet Burbank' grown at Lower Barrington (LB1) and at Sassafras (SSF).

\begin{tabular}{|c|c|c|c|c|c|c|c|}
\hline \multirow[t]{2}{*}{ Crop Data } & \multirow[t]{2}{*}{ Units } & \multicolumn{2}{|c|}{ RMSE } & \multicolumn{2}{|c|}{ N-RMSE (\%) } & \multicolumn{2}{|c|}{$\mathrm{EF}$} \\
\hline & & LB1 & SSF & LB1 & SSF & LB1 & SSF \\
\hline Tuber DM yield & t ha $^{-1}$ & 1.2 & 1.7 & 13.1 & 19.5 & 1.0 & 0.9 \\
\hline Stem dry biomass & $\mathrm{tha}^{-1}$ & 0.3 & 0.4 & 25.4 & 29.8 & 0.7 & 0.6 \\
\hline Leaf dry biomass & tha $^{-1}$ & 0.4 & 0.7 & 25.2 & 36.9 & 0.7 & 0.4 \\
\hline Aboveground dry biomass & $\mathrm{tha}^{-1}$ & 1.0 & 1.0 & 36.1 & 33.6 & 0.3 & 0.5 \\
\hline LAI & $m^{2} m^{-2}$ & 0.9 & 1.5 & 25.4 & 35.1 & 0.8 & 0.3 \\
\hline Tuber $\mathrm{N}$ uptake & $\mathrm{kg} \mathrm{N} \mathrm{ha}^{-1}$ & 25.3 & 27.0 & 20.6 & 21.1 & 0.9 & 0.9 \\
\hline Stem N uptake & $\mathrm{kg} \mathrm{N} \mathrm{ha}^{-1}$ & 5.3 & 20.5 & 22.1 & 59.5 & 0.6 & -0.3 \\
\hline Leaf $\mathrm{N}$ uptake & $\mathrm{kg} \mathrm{N} \mathrm{ha}^{-1}$ & 16.5 & 39.5 & 20.7 & 40.4 & 0.8 & 0.3 \\
\hline LMS & Number & 5.5 & 3.7 & 27.5 & 16.4 & 0.7 & 0.7 \\
\hline Plant height & $\mathrm{cm}$ & 10.7 & 16.1 & 18.1 & 24.7 & 0.8 & 0.6 \\
\hline
\end{tabular}

RMSE: Root mean square error, N-RMSE: Normalized root mean square error, EF: Modelling Efficient, DM: Dry matter, N: Nitrogen, LMS: number of leaves on each main stem, LAl: leaf area index 

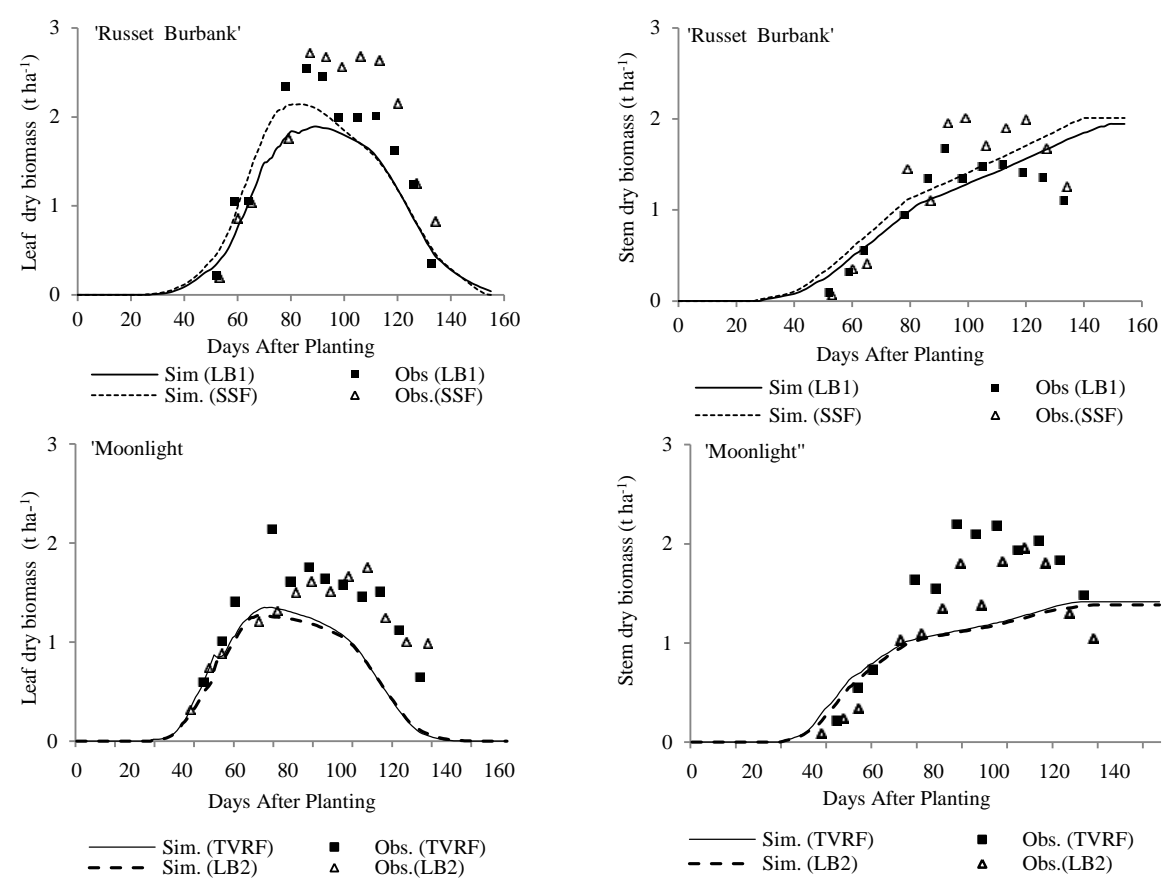

Fig 2. Change in observed and simulated stem and leaf biomass dry weight $\left(\mathrm{t} \mathrm{ha}^{-1}\right)$ over time for 'Russet Burbank' grown at LB1 and SSF and 'Moonlight' grown at LB2 and TVRF
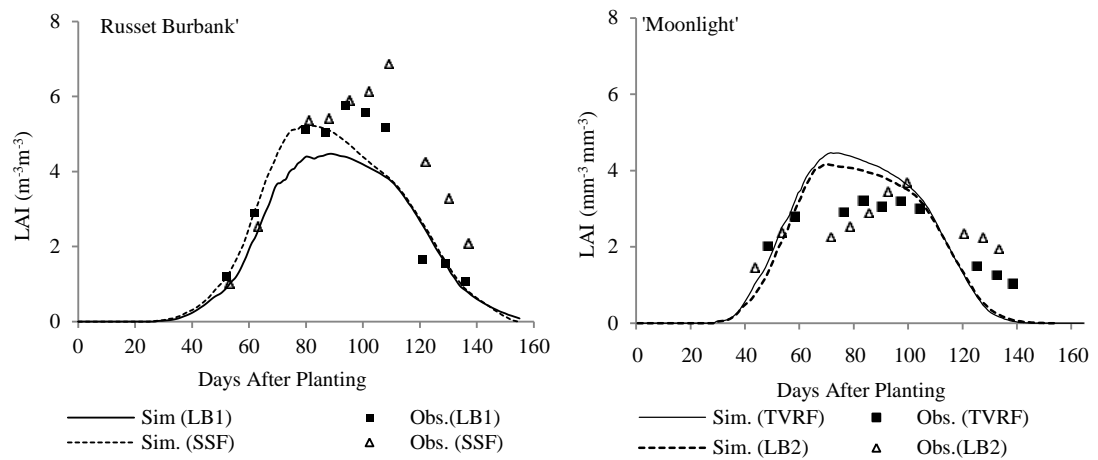

Fig 3. Change in observed and simulated leaf area index (LAI) over time for 'Russet Burbank' grown at LB1 and SSF and 'Moonlight' grown at TVRF and LB2.

Table 4. Statistical comparison between observed and simulated data for 'Moonlight' grown at Lower Barrington (LB2) and at Tasmanian Institute of Agriculture Vegetable Research Facility (TVRF) trial sites.

\begin{tabular}{|c|c|c|c|c|c|c|c|}
\hline \multirow[t]{2}{*}{ Crop Data } & \multirow[t]{2}{*}{ Units } & \multicolumn{2}{|c|}{ RMSE } & \multicolumn{2}{|c|}{ N-RMSE (\%) } & \multicolumn{2}{|c|}{$\mathrm{EF}$} \\
\hline & & TVRF & LB2 & TVRF & LB2 & TVRF & LB2 \\
\hline Tuber DM yield & tha $^{-1}$ & 1.2 & 1.2 & 12.7 & 16.3 & 1.0 & 1.0 \\
\hline Stem dry biomass & $\mathrm{tha}^{-1}$ & 0.6 & 0.4 & 41.7 & 32.7 & 0.0 & 0.6 \\
\hline Leaf dry biomass & $\mathrm{t} \mathrm{ha}^{-1}$ & 0.6 & 0.5 & 40.8 & 44.9 & -0.7 & -0.5 \\
\hline Above ground dry biomass & $\mathrm{tha}^{-1}$ & 0.8 & 0.5 & 27.8 & 21.7 & 0.4 & 0.7 \\
\hline LAI & $\mathrm{m}^{2} \mathrm{~m}^{-2}$ & 0.9 & 1.2 & 36.9 & 48.0 & -0.2 & -2.7 \\
\hline Tuber $\mathrm{N}$ uptake & $\mathrm{kg} \mathrm{N} \mathrm{ha}^{-1}$ & 32.6 & 29.0 & 28.5 & 36.8 & 0.8 & 0.7 \\
\hline Stem N uptake & $\mathrm{kg} \mathrm{N} \mathrm{ha}^{-1}$ & 10.3 & 8.4 & 46.8 & 49.6 & -2.3 & -0.5 \\
\hline Leaf N uptake & $\mathrm{kg} \mathrm{N} \mathrm{ha}^{-1}$ & 10.1 & 12.7 & 17.1 & 24.4 & 0.5 & 0.5 \\
\hline LMS & Number & 3.0 & 3.1 & 15.4 & 15.8 & 0.7 & 0.7 \\
\hline Plant height & $\mathrm{cm}$ & 13.0 & 12.6 & 21.5 & 24.8 & 0.7 & 0.6 \\
\hline
\end{tabular}

RMSE: Root mean square error, N-RMSE: Normalized root mean square error, EF: Modelling Efficient, DM: Dry matter, N: Nitrogen, LMS: number of leaves on each main stem, LAl: leaf area index 

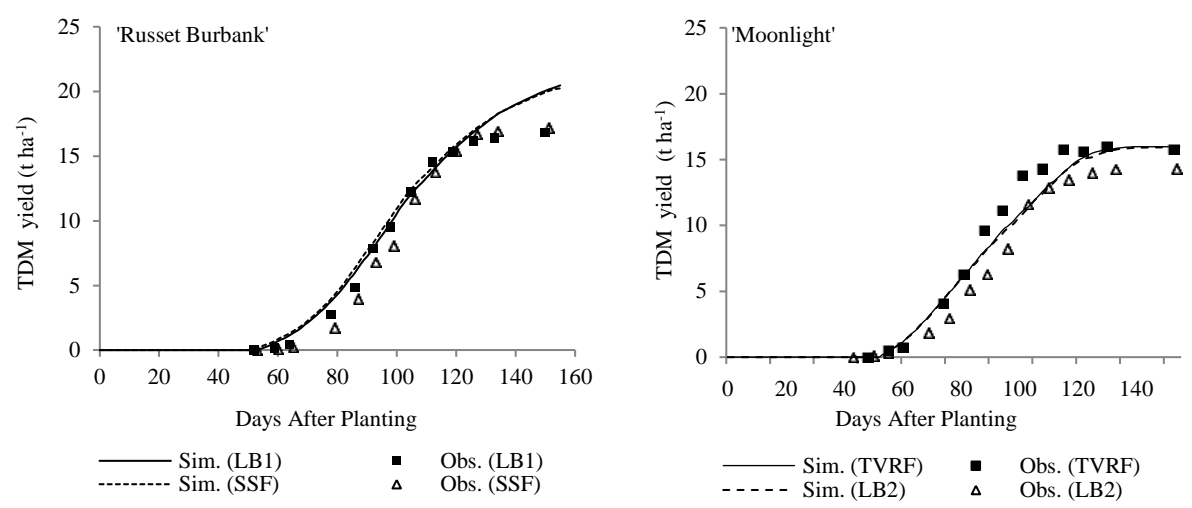

Fig 4. Change in observed and simulated tuber dry matter yield (t ha-1) over time for 'Russet Burbank' grown at LB1 and SSF and 'Moonlight' grown at TVRF and LB2.

Table 5. Pre-planting soil chemical properties at each of the on-farm monitoring plots in north-west Tasmania.

\begin{tabular}{|c|c|c|c|c|c|c|c|c|c|c|c|}
\hline $\begin{array}{l}\text { Depth } \\
\mathrm{cm}\end{array}$ & $\begin{array}{l}\mathrm{pH}-\mathrm{H}_{2} \mathrm{O} \\
(1: 5)\end{array}$ & $\begin{array}{l}\mathrm{EC} \\
\mathrm{dS} \mathrm{m}^{-1}\end{array}$ & $\begin{array}{l}\mathrm{P} \\
\mathrm{Mg} \mathrm{kg}^{-1}\end{array}$ & $\mathrm{~K}$ & $S$ & $\begin{array}{l}\text { OC } \\
\% \\
\end{array}$ & Total N & Total C & $\begin{array}{l}\mathrm{NO}_{3}-\mathrm{N} \\
\mathrm{Kg} \mathrm{ha}^{-1} \\
\end{array}$ & $\mathrm{NH}_{4}+$ & $\begin{array}{l}\mathrm{C} / \mathrm{N} \\
\text { Ratio }\end{array}$ \\
\hline \multicolumn{12}{|c|}{ L. Barrington 1 (LB1) } \\
\hline 00-15 & 7.0 & 0.08 & 225.0 & 505.9 & 6.5 & 3.9 & 0.3 & 4.4 & 8.4 & 10.1 & 13.2 \\
\hline $15-30$ & 6.9 & 0.08 & 184.0 & 448.9 & 8.8 & 3.5 & 0.3 & 3.9 & 8.7 & 9.7 & 13.0 \\
\hline $30-60$ & 6.5 & 0.11 & 74.0 & 341.8 & 55.9 & 2.5 & 0.2 & 2.9 & 5.6 & 10.0 & 13.7 \\
\hline \multicolumn{12}{|c|}{ Sassafras (SSF) } \\
\hline $00-15$ & 6.8 & 0.19 & 206.0 & 261.0 & 8.6 & 1.9 & 0.8 & 2.1 & 15.4 & 9.1 & 11.7 \\
\hline $15-30$ & 6.8 & 0.09 & 120.0 & 181.6 & 15.1 & 1.5 & 0.1 & 1.7 & 17.7 & 10.6 & 14.3 \\
\hline $30-60$ & 6.8 & 0.09 & 57.3 & 140.1 & 28.8 & 1.1 & 0.1 & 1.3 & 12.6 & 9.9 & 14.6 \\
\hline \multicolumn{12}{|c|}{ Tasmanian Institute of Agriculture Vegetable Research Facility (TVRF) } \\
\hline 00-15 & 6.6 & 0.14 & 125.0 & 540.2 & 29.1 & 3.3 & 0.4 & 4.0 & 28.5 & 12.8 & 9.8 \\
\hline $15-30$ & 6.5 & 0.12 & 58.1 & 287.9 & 66.0 & 1.9 & 0.2 & 2.4 & 15.5 & 11.2 & 11.7 \\
\hline $30-60$ & 6.5 & 0.12 & 48.0 & 258.9 & 75.6 & 1.7 & 0.2 & 2.2 & 11.9 & 10.1 & 12.0 \\
\hline \multicolumn{12}{|c|}{ L. Barrington 2 (LB2) } \\
\hline $00-15$ & 6.5 & 0.1 & 208.0 & 400.6 & 18.6 & 3.4 & 0.3 & 4.0 & 24.1 & 11.6 & 11.7 \\
\hline $15-30$ & 6.5 & 0.12 & 133.0 & 282.1 & 17.0 & 2.7 & 0.3 & 3.2 & 17.1 & 10.8 & 11.2 \\
\hline $30-60$ & 6.5 & 0.12 & 84.5 & 263.5 & 37.0 & 2.1 & 0.2 & 2.6 & 19.8 & 11.4 & 11.4 \\
\hline
\end{tabular}
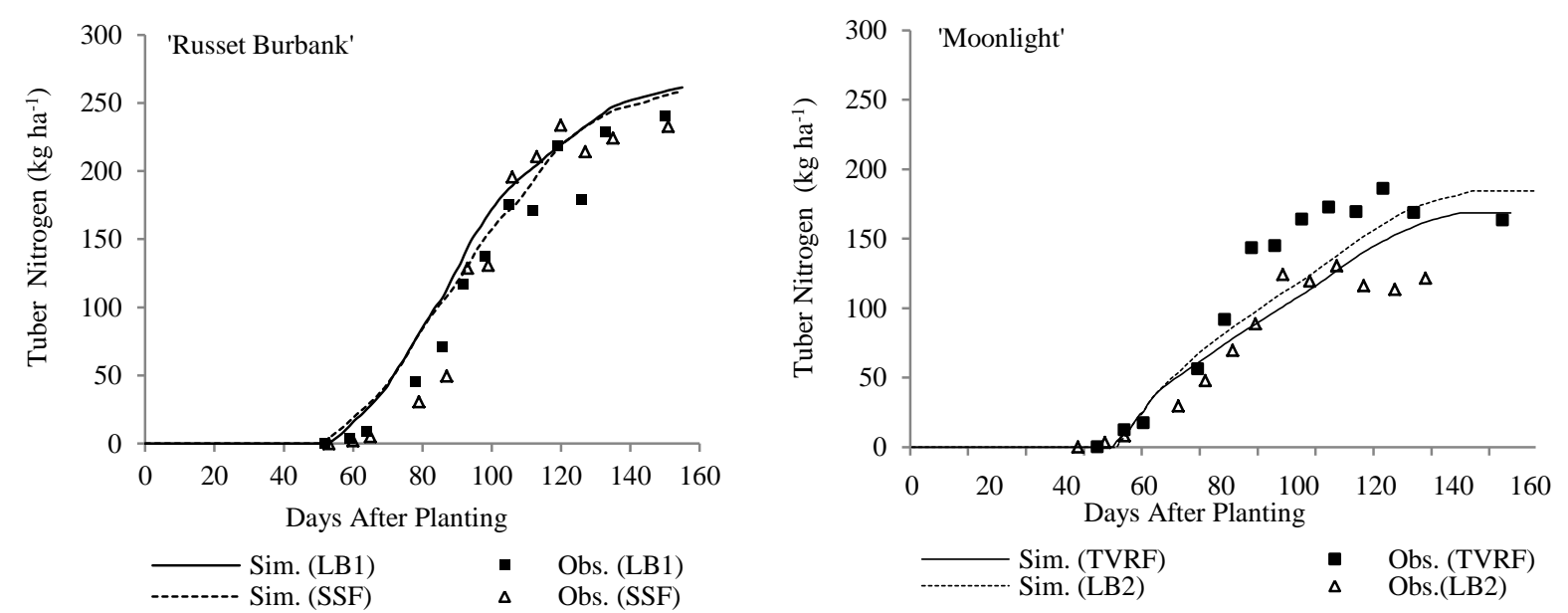

Fig 5. Change in observed and simulated total tuber nitrogen uptake over time for 'Russet Burbank' grown at SSF and LB1 and 'Moonlight' at TVRF and LB2. 
Table 6. Measured soil bulk density and hydraulic properties down to 1.2-m soil depth for each of the on-farm monitoring plots used as input parameter data to run the simulations

\begin{tabular}{|c|c|c|c|c|c|}
\hline \multirow{2}{*}{$\begin{array}{l}\text { Depth } \\
\mathrm{cm}\end{array}$} & \multirow{2}{*}{$\begin{array}{c}\mathrm{BD} \\
\mathrm{g} \mathrm{cc}^{-1}\end{array}$} & Air dry & LL15 & DUL & SAT \\
\hline & & \multicolumn{4}{|c|}{$\mathrm{mm} \mathrm{mm}^{-1}$} \\
\hline \multicolumn{6}{|l|}{ TVRF } \\
\hline $00-15$ & 1.29 & 0.30 & 0.31 & 0.46 & 0.52 \\
\hline $15-27$ & 1.21 & 0.33 & 0.33 & 0.46 & 0.51 \\
\hline $27-60$ & 1.17 & 0.24 & 0.23 & 0.47 & 0.53 \\
\hline $60-97$ & 1.19 & 0.38 & 0.38 & 0.51 & 0.52 \\
\hline $97-120$ & 1.20 & 0.41 & 0.41 & 0.46 & 0.52 \\
\hline \multicolumn{6}{|c|}{ L. Barrington 1} \\
\hline 00-15 & 1.18 & 0.30 & 0.37 & 0.46 & 0.58 \\
\hline $15-30$ & 1.21 & 0.37 & 0.37 & 0.49 & 0.51 \\
\hline $30-50$ & 1.23 & 0.40 & 0.40 & 0.49 & 0.52 \\
\hline $50-82$ & 1.20 & 0.39 & 0.39 & 0.49 & 0.52 \\
\hline $82-120$ & 1.15 & 0.36 & 0.36 & 0.49 & 0.57 \\
\hline \multicolumn{6}{|c|}{ L. Barrington 2} \\
\hline $00-15$ & 1.07 & 0.20 & 0.25 & 0.40 & 0.51 \\
\hline $15-30$ & 1.17 & 0.28 & 0.28 & 0.43 & 0.51 \\
\hline $30-66$ & 1.17 & 0.36 & 0.36 & 0.47 & 0.53 \\
\hline $66-90$ & 1.17 & 0.38 & 0.38 & 0.49 & 0.56 \\
\hline $90-120$ & 1.17 & 0.37 & 0.37 & 0.53 & 0.56 \\
\hline \multicolumn{6}{|c|}{ Sassafras } \\
\hline $00-14$ & 1.45 & 0.10 & 0.18 & 0.34 & 0.42 \\
\hline $14-28$ & 1.43 & 0.19 & 0.19 & 0.33 & 0.39 \\
\hline $28-43$ & 1.47 & 0.26 & 0.26 & 0.41 & 0.42 \\
\hline $43-79$ & 1.42 & 0.27 & 0.27 & 0.41 & 0.43 \\
\hline $79-120$ & 1.26 & 0.29 & 0.29 & 0.46 & 0.49 \\
\hline
\end{tabular}

BD: bulk density, LL15: crop lower limit, DUL: drained upper Limit, SAT: saturated water content
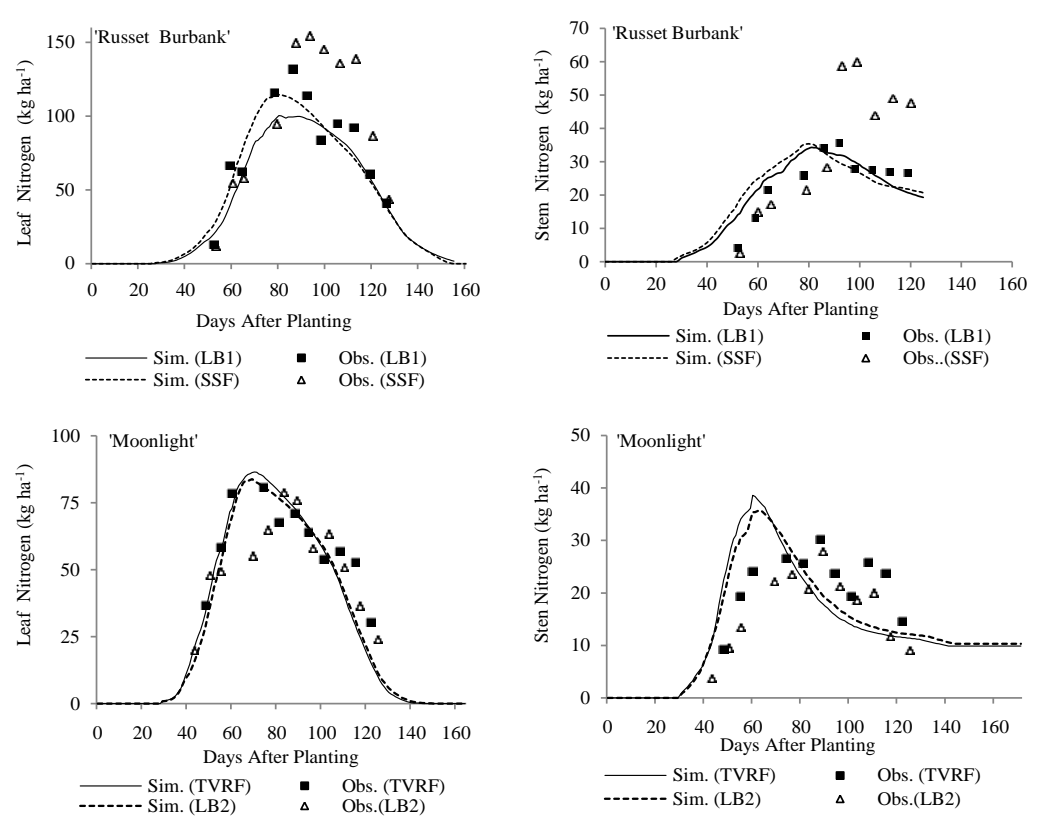

Fig 6. Change in observed and simulated aboveground biomass nitrogen uptake (stem and leaf dry weight) over time for 'Russet Burbank' grown at SSF and LB1 and 'Moonlight' at TVRF and LB2. 

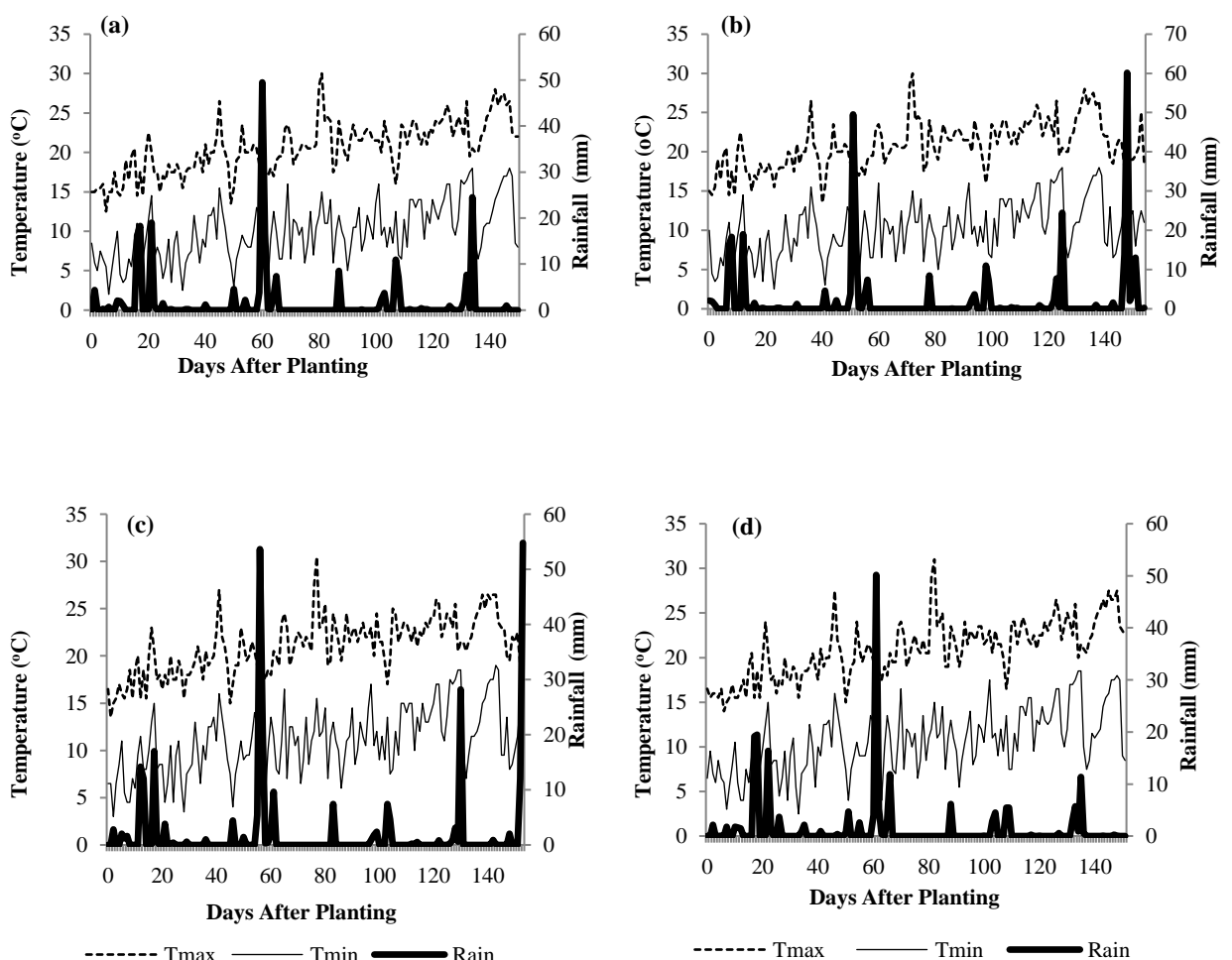

Fig 7. Daily maximum and minimum temperature and rainfall during the 2012-13 growing season at each of the on farm monitoring plots: LB1 (a), LB2 (b) TVRF (c) and Sassafras (d).

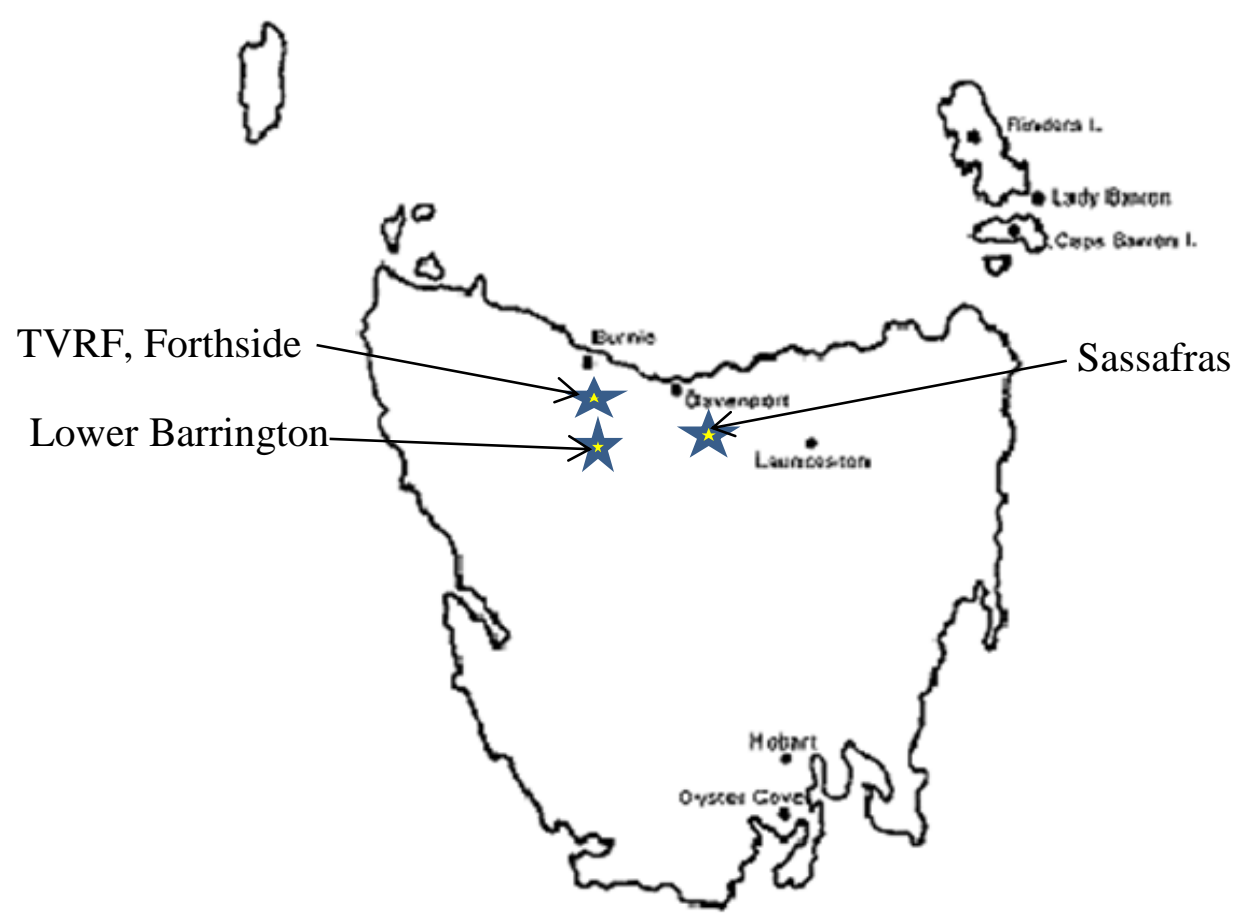

Fig 8. Map of Tasmania, Australia showing the location of the three study sites (Tasmanian Vegetable Research Facility, TVRF in Forthside, Lower Barington and Sassafras). 
data except at the latter growth stages when the simulated values were higher for 'Russet Burbank' in both sites and for 'Moonlight' at LB2 (Fig. 4).

Plant nitrogen uptake per organ: Tuber total nitrogen uptake (N-uptake) produced an overall good agreement between the simulated and observed values. N-RMSE values were $20.6 \%$ for 'Russet Burbank' at LB1 and $21.1 \%$ at SFF and for 'Moonlight' the values were $28.5 \%$ at TVRF and $36.8 \%$ at LB1 (Table 3 and 4). A high EF value, an average of 0.9 for 'Russet Burbank' and 0.7 for 'Moonlight' shows an excellent performance of the model in simulating tuber $\mathrm{N}$-uptake. Graphically, comparison of simulated values with observed values followed similar pattern although the model was biased towards over-estimation of tuber $\mathrm{N}$-uptake for 'Russet Burbank' at both sites and 'Moonlight' at LB2. At TVRF, simulated tuber nitrogen values were lower than the observed values (Fig.5).

There was variation in the simulation results for leaf and stem N-uptake for both cultivars (Fig.6). For 'Moonlight', the index of agreement was good for leaf $\mathrm{N}$-uptake for both sites (N-RMSE of $17.1 \%$ at TVRF and $24.4 \%$ at LB2) but poor for stem $\mathrm{N}$-uptake at both sites (N-RMSE > 30). For 'Russet Burbank', the agreement at LB1 was good for leaf and stem N-uptake with N-RMSE values of $20.7 \%$ and $22.1 \%$ respectively. The model performance was within acceptable levels with EF values of 0.8 (leaf) and 0.6 (stem) for 'Russet Burbank' at LB1. However, the model performance was poor for both leaf and stem nitrogen uptake with low EF values of 0.3 (leaf) and -0.3 (stem) for 'Russet Burbank' at SSF. Also the EF for stem N-uptake was poor for 'Moonlight' at both sites with values of -2.3 at TVRF and -0.5 at LB1

(Table 3 and 4).

Overall, the ability and precision of the APSIM-potato model to simulate TDM and $\mathrm{N}$-uptake was superior as evidenced by low N-RMSE and average to high EF values which indicates good agreement between the simulated and observed data compared to simulation of LAI, leaf and stem biomass with high N-RMSE and low EF values which indicates fair to poor agreement. The model captured the growth pattern over the growing period for all the crop parameters simulated: TDM, aboveground biomass, LAI and total plant nitrogen uptake per organ for both cultivars and across the on-farm plots.

The prediction varied per site with best-fit between the observed and actual data at LB1 for 'Russet Burbank' and at TVRF for 'Moonlight'. Simulation results for the phenology were reasonable, especially for the earlier growth stages. However, the model tended to underestimate the rate of senescence of haulms as the crop was harvested when the haulms were completely senesced and the model was still indicating the crop to be at late tuber (SC5) for 'Russet Burbank' and senescence (SC6) for 'Moonlight'. The overall agreement of aboveground biomass, LAI, leaf, and stem total nitrogen were modest and inferior to that of tuber dry matter yield, and tuber $\mathrm{N}$-uptake.

\section{Discussion}

APSIM-potato used in this study realistically reproduced the observed TDM and $\mathrm{N}$-uptake for the existing cultivar 'Russet Burbank' as well as for the cultivar 'Moonlight' parameterised for this study. Additionally, the model captured the development over the growing period for TDM, aboveground biomass, LAI and total plant nitrogen uptake across the on-farm plots and for both cultivars. The low $\mathrm{N}$ RMSE $(<20 \%)$ values obtained are an indication of high precision and reliability of the APSIM-potato model to predict tuber yield (Soler et al. 2007). Model performance in predicting tuber yield was similar to that obtained by Brown et al. (2011). It was also similar to prediction of tuber yield obtained in other studies for potato using LINTUL-POTATO (Condori et al. 2010) and SOLANUM (Carli et al. 2014).

There are several cultivar specific input parameters that determine growth pattern (duration and rate of various phenological stages) partitioning of assimilates, tuber number and size distribution and total tuber yield of each cultivar (Brown et al. 2011; Franke et al. 2011). 'Russet Burbank' has a higher potential yield than 'Moonlight' and the model captured the differences in potential yield of the two cultivars, predicting higher tuber yield for 'Russet Burbank' than Moonlight. Further, the model simulated the effect of management events and soil condition, with simulated tuber yield varying for each site. The prediction varied per site with best-fit between the observed and actual data at LB1 for 'Russet Burbank' and at TVRF for 'Moonlight. Each on-farm plot was managed differently by the growers but all with ample water and nutrient supply, under good weed management, pest and disease control. Tuber total N-uptake was also well simulated. However, the model performance in predicting aboveground biomass and LAI was relatively poor.

Crop growth models vary widely in their ability to simulate different organs of the plant (Boote et al. 2013; Pembleton et al. 2013; White et al. 2011). Also, there are differences in precision and ability of crop growth models to simulate different plant organs, and no single model is indisputably robust and accurate across cultivars, seasons and environments (Palosuo et al. 2011). For example, in a study by Pembleton et al. (2013), the APSIM model was shown to have excellent ability to predict forage crop yield and in most cases crop development for a range of forage crops but it performed poorly in simulating crop phenology of forage rape and forage sorghum. Wolf and Van Oijen (2003) reported a good prediction of TDM using LPOTCO-potato in half of the trial sites and poor prediction in the remaining half of the experimental locations. This seems to have been the case in the present study with good simulation results for tuber yield for both cultivars across the on-farm plots but with variation in leaf and stem state variables and also in phenology, $\mathrm{N}$-uptake per organ and LAI.

A possible reason for large deviations between simulated and observed leaf and stem biomass in the present study is that the model is programmed to simulate leaf organ without leaf petiole (leaf petiole is simulated in stem organ) while during the field measurement leaf petiole was included in sampling of leaf biomass. Thus N-RMSE and EF for aboveground biomass (leaf and stem combined) is better than for individual leaf and stem (Table 3 and 4). As shown graphically in Fig.2, stem organ is modelled as monotonically non-increasing/decreasing after the peak is achieved (i.e. stem senescence is not modelled) and this may explain the differences between simulated and observed stem dry biomass at the latter growth stages.

Given that APSIM-potato is a fairly new model (Brown et al. 2011) compared with other APSIM plant models and that this is the first time it has been tested outside New Zealand, 
the simulation results are encouraging. The simulation results presented here serve as a starting point for other researchers in the field of potato modelling with APSIMpotato and thus further refining is expected as more information is made available. There are no modelling studies in literature available on the APSIM-potato beside the one describing the model. Brown et al. (2011) reported an excellent best-fit for TDM and $\mathrm{N}$-uptake as well as for leaf and stem biomass and nitrogen uptake. Although such a high level of agreement between simulated and observed values were not obtained for aboveground biomass in the current study for the cultivars and sites investigated, the current modelling exercise has provided insights on the model performance under Tasmanian potato growing conditions.

It also increases confidence in the use of model to predict tuber yield and nitrogen content and in other research areas including scenario analysis and climate change impact studies on potato productivity. The model's inability to realistically simulate aboveground biomass, LAl and later growth stages of phenology might limit it application, particularly with respect to assessing the SC of the crop at any given period of crop growth.

\section{Materials and Methods}

\section{Plant materials}

Two commercial potato cultivars planted in October 2012 and managed by commercial growers were used for data collection: 'Russet Burbank' planted at SSF and LB1, and 'Moonlight' planted at TVRF farm and LB2. The two cultivars are the main processing cultivars, with the bulk of 'Russet Burbank' used for making frozen french fries while 'Moonlight', a fairly new processing cultivar introduced by Simplot Australia Ltd Pty is used mainly for making crisps (Mulcahy, personal communication, October 2012). The Tasmanian potato industry can be classified into three broad sectors; seed, fresh and processing, with processing accunting for $80 \%$ of the produce and $10 \%$ each for the seed and fresh market (DPIPWE 2014). 'Russet Burbank' was also selected because it is the only cultivar included in the APSIM-potato model that has been extensively tested (Brown et al. 2011) and there was need to evaluate the model performance under Tasmanian potato growing conditions. Since its introduction in 1960s, 'Russet Burbank' has dominated the industry due to its consistent yields of high quality tubers (Beattie 2010).

\section{Site description}

On-farm monitoring plots were established in north-west Tasmania within well-managed potato fields grown during the 2012/13 cropping season where all the management events were carried out by the farmer and no additional treatments were introduced. All the four potato fields belonged to commercial growers contracted by Simplot Australia Ltd and the growers followed the recommended agronomic practices for production of processing potatoes as advised by a field agronomist. There were four different on-farm monitoring plots located at Tasmanian Institute of Agriculture Vegetable Research Facility (TVRF) (41.01S, 146.26E, $125 \mathrm{AMSL}$ ), two plots at Lower Barrington (LB1 and LB2) (41.26S, 146.30E, $229 \mathrm{AMSL}$ ) and (41.26S, 146.30E, 233 AMSL), and one plot at Sassafras (SSF) (41.25S, 146.5E, 115
AMSL) (Fig 8.) At planting, soil samples down to 0.6-m depth were taken from each of the four on-farm plots. Samples were chemically analysed using analytical techniques described in Rayment and Lyons (2011) (Table 5) at AgVita Analytical Laboratories, Devonport, Tasmania. Samples were analysed using the increments: 0-15, 15-30, 30-60 cm.

\section{Collection of field data}

Crop measurements: Crop data were collected on a weekly basis starting at $50 \%$ tuber emergence (EM). EM was measured by counting the number of emerged plants in each on-farm monitoring plot and was assumed to have taken place when $50 \%$ of the sprouts had emerged from the soil surface. For each sequential harvesting, 2 adjacent plants were harvested from 6 locations within the on-farm plot, giving a total of 12 plants per plot. Growth and development parameters including the height of the main stem (MS), number of MS, number of tubers per plant and the number of leaves appearing on each MS for each sampled plant were recorded immediately after each sequential harvesting before the plants were separated into leaves ( $L$, the whole compound leaf including petioles), stems (S) which included below and aboveground stems and tubers $(T)$. Roots and stolons were discarded because they are not economically important, difficult to measure, and are a minor component of biomass. Fresh weights of each plant organ (L,S,T) were recorded separately. The dry weight of each component was determined by oven drying the subsamples at $90{ }^{\circ} \mathrm{C}$ to a constant weight for at least 48 hours. Where samples were too bulky, a sub-sample of approximately $200 \mathrm{~g}$ per organ was taken for drying. Tubers were washed and chopped before drying. Samples for $\mathrm{N}$ Analysis were oven dried at $60{ }^{\circ} \mathrm{C}$ for 48 hours. Total nitrogen in each plant organ was determined by the Dumas high-temperature combustion method (Rayment and Lyons 2011).

Leaf Area index (LAI): LAl was measured on a fortnightly basis using SunScan (SS1, AT Delta-T Devices Ltd, UK), starting from the EM date. To minimise the effect of solar Zenith angle, LAI measurements were taken at around noon. For each sampling date, 12 measurements were taken per on-farm plot, in which six of the measurements were centred over rows and the other six measurements were centred over furrows. The measurements over the rows and furrows were taken alternately. All the measurements were averaged to obtain a single LAl value per on-farm plot for each sampling date.

Bulk density and Soil hydraulic properties: After harvesting, freshly-dug soil pits were used to describe and characterise the soils at each on-farm plot (Table 6). Depending on the soil horizon at each site, samples were collected at 0.15 - to 0.3-m intervals from soil surface down to $1.2 \mathrm{~m}$. Soil cores used for determination of bulk density (BD) were collected using rings with a height of $50 \mathrm{~mm}$ and an internal diameter of $74 \mathrm{~mm}$, with cores taken in triplicate down the soil profile. Soil cores were oven dried at $105^{\circ} \mathrm{C}$ to a constant weight for at least 48 hours. BD expressed in $\mathrm{g} \mathrm{cm}^{-3}$ is the ratio of dry soil mass to the total volume of dry soils (Cresswell and Harmilton 2002). Soil cores for determination of soil water properties: plant available water content at saturation (SAT), drained upper limit (DUL) and crop lower limit (LL15) were collected using rings with a height of $20 \mathrm{~mm}$ and an internal 
diameter of $4.8 \mathrm{~cm}$ taken in triplicate down the soil profile. The rings were hammered horizontally into the profile and carefully trimmed both at the top and bottom. A 1600 Pressure Plate Extractor 5 bar (Soil Moisture Equipment Corporation, USA) was used to determine SAT, DUL and LL15 equilibrated at specified matric potentials: $0 \mathrm{kPa}$ for SAT, -10 $\mathrm{kPa}$ for DUL and -1500 kPa for LL15. Soils for each site were parameterised with potato root exploration factor (XF) and water extraction coefficient (KL). A value of 1 of XF was used for all the soil layers down to a maximum depth of $90 \mathrm{~cm}$ based on the assumption that the rooting capability between soil layers was not restricted. KL values were adjusted based on the fact that approximately $85 \%$ of potato roots are concentrated in the upper $30 \mathrm{~cm}$ soil layer (Opena and Porter 1999). Thus KL values of $0.1(0-30 \mathrm{~cm}), 0.06$ (30$60 \mathrm{~cm}), 0.03(60-90 \mathrm{~cm})$ and 0.02 were set for soil depths below $90 \mathrm{~cm}$.

\section{Weather data}

Daily weather data used to run the simulations were obtained from SILO meteorological database (http://www.longpaddock.qld.gov.au/silo/). Daily maximum temperature (Tmax) and minimum temperature (Tmin), and rainfall for each of the four on-farm monitoring plots during the cropping season are presented in Fig. 7 and the averages in Table 1. With a Tbase temperature of $2{ }^{\circ} \mathrm{C}$ (Brown et al., 2011) accumulated growing day degrees (GDD, ${ }^{\circ} \mathrm{Cd}$ ) during the growing season ranged from 2004 to $2164{ }^{\circ} \mathrm{Cd}$ (Table 1). GDD are calculated from daily temperature data by taking the mean value of the daily maximum and minimum temperatures and subtracting Tbase (Mix et al. 2010).

\section{Model parameterization and evaluation}

The Model: This study used APSIM-potato (version 7.5), a new plant model built in the Plant Modelling Framework (Brown et al. 2011; Brown et al. 2014). APSIM-potato is a comprehensive daily time-step, deterministic crop model that integrates with the APSIM soil, SOILN, management, and user interface components. The model predicts biomass, tuber yield, N-uptake, water use efficiency of the potato plant, soil water variables and other plant parameters on a daily basis in response to inputs of daily weather data, soil characteristics, crop parameters and management events. It uses a constant RUE (Radiation Use Efficiency) value of $1.2 \mathrm{~g}$ dry matter $\mathrm{MJ}^{-1}$ of intercepted radiation. The water stress factor ( $\mathrm{fw}$ ) is optimum at 1.0 when the crops are supplied with adequate water and will decline to zero when the soil moisture is nearing the crop lower limit (LL15). Most potato growth crop models including APSIM-potato do not simulate the effects of abiotic factors (weeds, pests and diseases) (Raymundo et al. 2014).

At daily average temperatures of $2{ }^{\circ} \mathrm{C}$ (Tbase), the temperature stress factor $(\mathrm{ft}$ ) values rises from zero to a maximum value of 1.0 at daily mean temperatures of between $12{ }^{\circ} \mathrm{C}$ and $24^{\circ} \mathrm{C}$. Above $24^{\circ} \mathrm{C}$, the $\mathrm{ft}$ values declines to zero at $34{ }^{\circ} \mathrm{C}$. APSIM simulates crop water stress using the ratio of soil water supply to potential water demand with a value of 1.0 indicating no water stress and the lower the values, the more the water stress (Lobell et al., 2015).

Using inputs of tuber planting density and the number of MS per tuber, the model calculates the population density of primary stem units which in turn are used to predict the rate of appearance, expansion, size and duration of individual leaves on the primary stems and the occurrence of branching. APSIM-potato partitions dry matter assimilates into four state variables; leaf, stem, root and tuber.

Model parameterization: Daily weather data (global solar radiation, rainfall, maximum and minimum temperatures) used in the simulations are presented in Fig.1. Soil chemical and soil hydraulic properties (Table 6), crop data, and management events (Table 2) were used as parameter input data to run the simulations. Initial soil water content was set at $50 \%$ filled from the top. Crop growth models require parameterization of the default crop parameters before the models are applied in confidence with new cultivars. Cultivar specific parameters determines tuber yield of each cultivar (Franke et al. 2011). Thus for 'Moonlight', we first parameterised the model by changing key cultivar-specific parameters as the cultivar is distinctively different from 'Russet Burbank'. Measured data for 'Moonlight' were grouped into data (number of main stem plant ${ }^{-1}$, number of leaves $\mathrm{MS}^{-1}$ ) that were used to set up the model and aboveground biomass, tuber yield, N-uptake, LAl used to evaluate the model.

Parameterization for 'Moonlight' was guided by field observations and published descriptors of 'Moonlight' (Anderson et al., 2004). We adjusted four dominant cultivar specific parameters: (i) Main stem final node number, (ii) Stem branching rate, (iii) Leaf maximum area, and (iv) Leaf lag duration. The other cultivar-specific parameters and all crop-specific constants were assumed to be equal to the values for 'Russet Burbank' and were left unchanged.

Model evaluation: The parameterized APSIM-potato was used to run the simulations, and the performance of the model was assessed by comparing simulated crop data with the measured data. Measured biomass (leaf and stem combined) and tuber dry matter yield were compared with the simulated data. All comparisons were done on a dry weight basis. A crop growth model is considered robust if it can simulate observed data with acceptable accuracy. Several statistical indicators are used to quantify model accuracy. In this study the model was evaluated using normalized Root mean squared error (N-RMSE expressed as $\%)$, an error index statistic that gives a measure of the relative difference of simulated versus observed data (Soler et al. 2007) and modelling efficiency (EF), a dimensionless statistic that gives an assessment of model performance (Moriasi et al. 2007). RMSE (Eq.1) (Soler et al. 2007) was normalised by the mean of observed values. The agreement between the simulated and the observed data is considered excellent if the N-RMSE value is less than $10 \%$; a value of 10 $20 \%$ is considered good; a value of $20-30 \%$ is viewed as fair; and the agreement is considered poor if the N-RMSE value is greater than 30\% (Soler et al. 2007). An EF (Eq. 2) (Krause et al. 2005) value of 1.0 is considered excellent; values ranging from 0.0 to $>1.0$ are considered acceptable; and the level of performance is considered poor if the values are less than 0.0 (Moriasi et al. 2007). RMSE and EF are often used in model performance evaluation, including in previous potato modelling studies (Carli et al. 2014; Condori et al. 2010; Tubiello et al. 2002).

$$
\begin{aligned}
& \mathrm{N}-\mathrm{RMSE}=\sqrt{\frac{\sum_{i=1}^{n}\left(\boldsymbol{S}_{i}-\boldsymbol{O}_{i}\right)^{2}}{n}} \times \frac{100}{\mathrm{M}} \\
& E F=1-\frac{\sum_{i=1}^{n}\left(O_{i}-S_{i}\right)^{2}}{\sum_{i=1}^{n}\left(O_{i}-\overline{0}\right)^{2}}
\end{aligned}
$$


Where $\mathrm{n}$ is the number of observations, $S_{i}$ refers to the simulated values, $O_{i}$ refers to the observed values of potato crop data e.g. biomass dry weight or tuber dry matter and $\mathrm{M}$ (Eq. 1) and Ō ( Eq. 2) refers to the mean of the observed values.

\section{Conclusion}

Our results provide insights on the model performance under Tasmanian potato growing conditions and show that the model is a suitable candidate for simulating tuber yield and nitrogen content. The ability of the model to realistically reproduce the observed TDM and $\mathrm{N}$-uptake for the base cultivar 'Russet Burbank' as well as for 'Moonlight' has increased confidence in its application. Additionally, the model captured the growth pattern over the growing period for tuber yield, aboveground biomass, LAl and total plant Nuptake across the on-farm plots and for both cultivars. However, modification of some key cultivar specific parameters is needed to improve the predictions of other plant organ growth and development. As part of refining the model, more testing of its performance is recommended with additional locations, years, and management options. Further research is required to determine the key cultivar specific input parameters within the crop module such as phenology, leaf area, leaf duration, and coefficients that needs further refinement to improve the model's ability to simulate other plant organs in addition to the tuber.

\section{Acknowledgements}

The work presented in this paper was funded by AusAID and the Tasmania Institute of Agriculture (TIA). We would like to thank Frank Mulcahy and Scott Morris of Simplot Australia Ltd. for facilitating access to the potato fields in north-west Tasmania.Special gratitude goes to the four potato growers for allowing us to use their potato fields to conduct the investigations. We wish to express our gratitude to those who gave us access to equipment and facilities and those who gave us special technical support in their respective areas of expertise. They include Marcus Hardie, David Phelan, Pete Johnson, Bill Cotching, John McPhee, James Phil, Keith Pembleton and David Ratkowsky of University of Tasmania.

\section{References}

ABS Catalogue 7121.0 - Agricultural Commodities, Australia, various years (2014) Australian Bureau of Statistics. http://www.abs.gov.au/ausstats/abs@.nsf/mf/7121.0. Accessed 21 March 2015.

Anderson JAD, Lewthwaite SL, Genet RA \& Braam WF (2004) 'Moonlight': A new dual-purpose main crop potato (Solanum tuberosum) cultivar. New Zealand Journal of Crop and Horticultural Science 32: 153 - 156.

AUSVEG (2014) Potatoes Australia. In: AUSVEG. https://ausveg.worldsecuresystems.com/resources/statisti cs/domestic-industry.htm. Accessed 17 March 2015.

Beattie B (2010) The effects of seed production practices on the productivity of the succeeding ware potato crop. PhD, University of Tasmania, Hobart, Australia.

Birch PR, Bryan G, Fenton B, Gilroy EM, Hein I, Jones JT, Prashar A, Taylor MA, Torrance L \& Toth IK (2012) Crops that feed the world 8: Potato: are the trends of increased global production sustainable? Food Security 4: 477- 508.

Boote K, Jones J, White J, Asseng S \& Lizaso J (2013) Putting mechanisms into crop production models. Plant, cell \& environment 36:1658 - 1672.

Boote K, LH A, Prasad P \& Jones J (2010) Testing effects of climate change in crop models. Handbook of climate change and agroecosystems. Imperial College Press, London:109-129

Bradshaw JE \& Bonierbale M (2010) Potatoes Root and Tuber Crops. Springer, p 1-52.

Brown HE, Huth N \& Holzworth D (2011) A potato model built using the APSIM Plant .NET Framework. Paper presented at the 19th International Congress on Modelling and Simulation, Perth, Australia.

Brown HE, Huth NI, Holzworth DP, Teixeira El, Zyskowski RF, Hargreaves JN \& Moot DJ (2014) Plant modelling framework: software for building and running crop models on the APSIM platform. Environmental Modelling \& Software 62: 385 - 398.

Carli C, Yuldashev F, Khalikov D, Condori B, Mares V \& Monneveux P (2014) Effect of different irrigation regimes on yield, water use efficiency and quality of potato (Solanum tuberosum L.) in the lowlands of Tashkent, Uzbekistan: a field and modeling perspective. Field Crops Research 163: 90 - 99.

Condori B, Hijmans RJ, Quiroz R \& Ledent J-F (2010) Quantifying the expression of potato genetic diversity in the high Andes through growth analysis and modeling. Field Crops Research 119:135 - 144.

Cresswell H \& Harmilton GJ (2002) Bulk Density and Pore Space Relations. In: McKenzie N, Coughlan K \& Cresswell H (eds) Soil physical Measurement and Interpretation For Land Evaluation. vol 5. CSIRO, Toowoomba, Australia, p 35 $-59$.

DPIPWE (2014) Potato Market Profile. Department of Primary Industries, Parks, Water and Environment.http://dpipwe.tas.gov.au/Documents/Potato \%20Profile\%20updated\%20March\%202014.pdf. Accessed March 182015.

DPIPWE (2015) Water for Profit Program. Department of Primary Industries, Parks, Water and Environment. http://dpipwe.tas.gov.au/agriculture/water-for-profitprogram. Accessed March 232016.

Statistics Division (2015) Food and Agriculture Organization. http://faostat3.fao.org/. Accessed March 212015.

Fleisher DH, Condori B, Quiroz R, Alva A, Asseng S, Barreda C, Bindi M, Boote KJ, Ferrise R \& Franke AC (2017) A potato model intercomparison across varying climates and productivity levels. Global change biology 23: 1258 - 1281.

Franke A, Steyn J, Ranger K \& Haverkort A (2011) Developing environmental principles, criteria, indicators and norms for potato production in South Africa through field surveys and modelling. Agricultural Systems 104: 297 - 306.

Haverkort AJ, Franke AC, Engelbrecht FA \& Steyn JM (2013) Climate Change and Potato Production in Contrasting South African Agro-ecosystems 1. Effects on Land and Water Use Efficiencies. Pot Res. 56: 31 - 50.

Holzworth D, Huth NI, Zurcher EJ, Herrmann NI, McLean G, Chenu K, van Oosterom E, Snow V, Murphy C \& Moore A (2014) APSIM-evolution towards a new generation of agricultural systems simulation. Environmental Modelling \& Software 62: 327 - 350. 
Krause P, Boyle D \& Bäse F (2005) Comparison of different efficiency criteria for hydrological model assessment. Advances in Geosciences 5: 89 - 97.

Mix K, Rast W \& Lopes VL (2010) Increases in growing degree days in the Alpine Desert of the San Luis Valley, Colorado. Water, Air, and Soil Pollution 205: 289 - 304.

Moriasi D, Arnold J, Van Liew M, Bingner R, Harmel R \& Veith $T$ (2007) Model evaluation guidelines for systematic quantification of accuracy in watershed simulations. Trans. Asabe 50: 885 - 900.

Opena GB \& Porter GA (1999) Soil management and supplemental irrigation effects on potato: II. Root growth. Agronomy Journal 91: 426 - 431.

Palosuo T, Kersebaum KC, Angulo C, Hlavinka P, Moriondo M, Olesen JE, Patil RH, Ruget F, Rumbaur C \& Takáč J (2011) Simulation of winter wheat yield and its variability in different climates of Europe: A comparison of eight crop growth models. European Journal of Agronomy 35 :103114.

Pembleton K, Rawnsley R, Jacobs J, Mickan F, O'Brien G, Cullen B \& Ramilan T (2013) Evaluating the accuracy of the Agricultural Production Systems Simulator (APSIM) simulating growth, development, and herbage nutritive characteristics of forage crops grown in the south-eastern dairy regions of Australia. Crop and Pasture Science 64: $147-164$

Rayment GE \& Lyons DJ (2011) Soil chemical methods: Australasia, vol 3. CSIRO publishing, Toowoomba, Australia. Raymundo R, Asseng S, Cammarano D \& Quiroz R (2014) Potato, sweet potato, and yam models for climate change: A review. Field Crops Research 166: 173 - 185.

Saue T \& Kadaja J (2014) Water limitations on potato yield in Estonia assessed by crop modelling. Agricultural and Forest Meteorology 194: 20 - 28.

Soler CMT, Sentelhas PC \& Hoogenboom G (2007) Application of the CSM-CERES-Maize model for planting date evaluation and yield forecasting for maize grown offseason in a subtropical environment. European Journal of Agronomy 27: 165 - 177.
Tubiello F, Rosenzweig C, Goldberg R, Jagtap S \& Jones JW (2002) Effects of climate change on US crop production: simulation results using two different GCM scenarios. Part I: Wheat, potato, maize, and citrus. Climate research 20: $259-270$.

White JW, Hoogenboom G, Kimball BA \& Wall GW (2011) Methodologies for simulating impacts of climate change on crop production. Field Crops Research 124: 357 - 368.

Wolf J \& Van Oijen M (2003) Model simulation of effects of changes in climate and atmospheric $\mathrm{CO} 2$ and O-3 on tuber yield potential of potato (cv. Bintje) in the European Union. Agriculture, ecosystems \& environment 94: 141 - 157. 